\title{
SURVIVAL OF ESCHERICHIA COLI O157:H7 ON RAW MATURE GREEN TOMATOES DURING STORAGE TEMPERATURE ABUSE
}

\begin{tabular}{|c|c|}
\hline \multicolumn{2}{|c|}{ 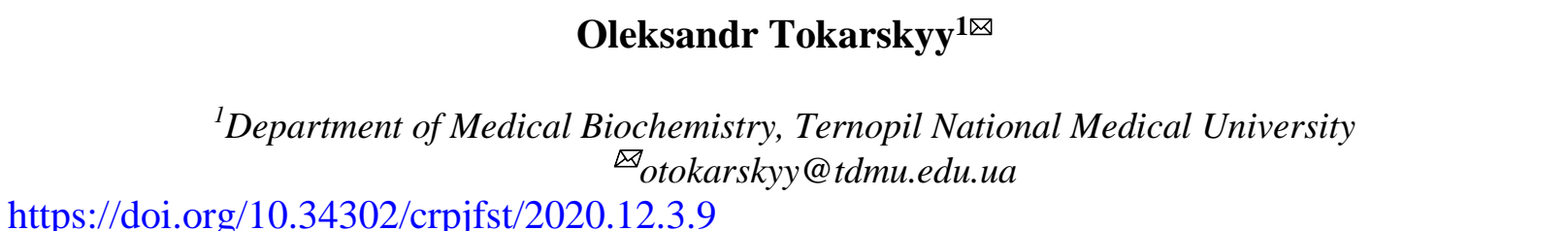 } \\
\hline $\begin{array}{l}\text { Article history: } \\
\text { Received: } \\
\quad 5 \text { May } 2020 \\
\text { Accepted: } \\
\quad 25 \text { August } 2020 \\
\end{array}$ & $\begin{array}{l}\text { ABSTRACT } \\
\text { Tomatoes are important agricultural commodity, which are often consumed } \\
\text { fresh without final pathogen elimination step. Being harvested as mature } \\
\text { green fruit with further ripening, their shelf life can be greatly increased after } \\
\text { harvesting. It is important to immediately cool down harvested fruit to } 15^{\circ} \mathrm{C}\end{array}$ \\
\hline $\begin{array}{l}\text { Keywords: } \\
\text { E. coli O157:H7; } \\
\text { Survival; } \\
\text { Tomatoes; } \\
\text { Temperature abuse. }\end{array}$ & $\begin{array}{l}\text { to avoid decay and optimize storage. The purpose of the current study was } \\
\text { to evaluate survival of five-strain Escherichia coli O157:H7 cocktail on the } \\
\text { undamaged surface of green mature tomatoes during } 4 \text {-day storage at } 25^{\circ} \mathrm{C} \text {, } \\
15^{\circ} \mathrm{C} \text {, and temperature abuse conditions, such as slow ramping from } 25^{\circ} \mathrm{C} \text { to } \\
15^{\circ} \mathrm{C} \text { over duration of the experiment. Pathogen numbers declined } 1.5 \mathrm{log} \\
\text { units from theoretical inoculation level of } 6.8 \log _{10} \text { cfu/mL of rinsate to } 5.3 \\
\log _{10} \mathrm{cfu} / \mathrm{mL} \text { upon } 90 \text { minutes inoculum drying, and significantly continued } \\
\text { to decline during storage at both } 25^{\circ} \mathrm{C} \text { and } 15^{\circ} \mathrm{C} \text {, as well as temperature abuse } \\
\text { conditions, resulting in final counts of } 1.5,2.4 \text {, and } 2.6 \log _{10} \mathrm{cfu} / \mathrm{mL} \text { on day } \\
4 \text { for } 25^{\circ} \mathrm{C}, 15^{\circ} \mathrm{C} \text {, and ramp, respectively. The fastest decline was observed } \\
\text { in } 25^{\circ} \mathrm{C} \text { stored tomatoes. Placing tomatoes immediately into } 15^{\circ} \mathrm{C} \text { incubator, } \\
\text { or gradually decreasing storage temperature over a } 4 \text {-day period, preserved } \\
\text { the state of viability of E.coli } \mathrm{O} 157: \mathrm{H} 7 \text { comparing to other treatment. }\end{array}$ \\
\hline
\end{tabular}

\section{Introduction}

Based on the data from the United States Department of Agriculture, tomatoes are among the most popular vegetables in the United States, with 29.6 pounds consumed per person, including 58\% eaten as canned product, in 2016 alone (USDA-ERS, 2016). Salmonellaassociated tomato outbreaks were observed on numerous occasions (CDC 2002; Cummings et al. 2001; Croby et al. 2004). Natural microflora on the surface of raw tomatoes include variety of groups of bacteria, including Gram positive, Gram negative, pathogenic, opportunistic pathogens, and non-pathogenic (Tokarskyy and Korda, 2019a).

It is a common knowledge that enteric pathogens may be introduced onto tomatoes through irrigation water, bird droppings, wash water, handling by workers, or contaminated surfaces (Beuchat and Ryu, 1997). Tomatoes are commonly eaten fresh with no processing steps present to eliminate bacterial pathogens, such as cooking (Tokarskyy et al., 2009) and irradiation (Schilling et al., 2009). It was noted that pathogen will grow in the tomato even at ambient temperature, if introduced through wounds, stem scars, and abrasions (Zhuang et al., 1995; Das et al., 2006; Shi et al., 2007). However, researchers agree that counts of pathogenic Gram-negative enteric bacteria will decline on undamaged surface over time, depending on bacterial species, strain, resuspension medium, humidity, and tomato storage temperature (Tokarskyy et al., 2018; Tokarskyy and Korda, 2019b; Tokarskyy and Schneider, 2019). Because of E. coli O157:H7 not being implicated in tomato-related poisoning to the best of our knowledge so far, 
most research related to tomato safety was done with Salmonella spp. Hirai (1991) mentioned that Salmonella spp. have better survival rates after drying on the surfaces, comparing to Escherichia coli. For example, Lang et al. (2004) showed that spot-inoculated tomatoes with Salmonella spp. or E. coli $\mathrm{O} 157: \mathrm{H} 7$ showed counts decline by 2.20 and $3.17 \log$ units, respectively, after twenty four hours inoculum post-drying. A few studies have shown possibility for Salmonella Montevideo to colonize and grow on the surface of healthy undamaged tomatoes (Zhuang et al., 1995; Ituriaga et al., 2007), but those records might be due to the presence of microabrasions on the surface where pathogen could have been introduced, or possibility of the pathogen introduction onto the stem part during inoculation via complete immersion. Earlier we showed that low contamination levels of $E$. coli O157:H7 do not persist on the surface of mature green, breaker stages, or pink tomatoes, if abovementioned surface is intact or bruised, at $15^{\circ} \mathrm{C}$ and $25^{\circ} \mathrm{C}$ (Tokarskyy et al., 2018), while high level contamination may stay longer, depending on tomato storage temperature, diluent for pathogen resuspension, and humidity (Tokarskyy and Korda, 2019b).

It is not feasible, due to economic and marketing reasons, as well as due to mass production, to harvest tomatoes as table-ripe red fruit in the United States. Therefore, they are harvested as "mature green" with further ripening, either naturally, or using ethylene gas (Kader et al., 1978). Such techniques, as lower temperature storage (less than $20^{\circ} \mathrm{C}$, but above $12.5^{\circ} \mathrm{C}$ ) and low oxygen storage (4\%), delay ripening and make tomatoes available over longer period of time. Inaba and Chachin (1989) noted that both the respiration rate and the ethylene production were suppressed in green mature tomatoes stored at 5,10 , and $35^{\circ} \mathrm{C}$, but not at 15 or $25^{\circ} \mathrm{C}$, and fruit injury was obvious at $40^{\circ} \mathrm{C}$. However, Batu (2003) wrote, that $15^{\circ} \mathrm{C}$, but not $13^{\circ} \mathrm{C}$, was suitable for certain variety of mature green tomatoes storage to improve keeping quality without influencing flavor and further maturation into red fruit. Additionally, Mulholand et al. (2003) wrote, that "heat pulses" of $22.2^{\circ} \mathrm{C}$ to $25.9^{\circ} \mathrm{C}$ over a 3 -day or 7 -day periods significantly increased fruit defects and yields in green mature tomatoes in the week immediately following the end of a heat-pulse treatment. A three-day heat-pulse with a mean temperature of $23.0^{\circ} \mathrm{C}$ was sufficient to cause a $10 \%$ loss of fruit classified as class I (Mullholand et al., 2003). Therefore, it is important to cool down green mature tomatoes to $15^{\circ} \mathrm{C}$ as soon as possible after harvesting to increase shelf life of the product without damaging flavor and quality during ripening in the future.

The objective of the current study was to determine survival rates of $E$. coli $\mathrm{O} 157: \mathrm{H} 7$ at high contamination level for four days on the surface of unwashed and undamaged green mature tomatoes stored at room temperature $\left(25^{\circ} \mathrm{C}\right)$, cool temperature $\left(15^{\circ} \mathrm{C}\right)$, and during storage temperature abuse conditions $\left(25^{\circ} \mathrm{C}\right.$ to $15^{\circ} \mathrm{C}$ gradual ramp within four days). The hypothesis was that slower cooling may influence $E$. coli $\mathrm{O} 157: \mathrm{H} 7$ adaptation and cause better survival of the pathogen on the tomato surface.

\section{Materials and methods}

\subsection{Rifampin preparation}

Rifampin (rif, Fisher Scientific, BP26795)

0.4 grams was dissolved in $40 \mathrm{~mL}$ methanol (HPLC grade, Fisher Scientific), resulting in $10,000 \mathrm{ppm}$ rif stock solution, filter-sterilized (0.2 micron nylon filter, Fisher Scientific), and stored refrigerated $\left(4^{\circ} \mathrm{C}\right)$ in the darkness for no longer than one month. Rifampin was added to the cooled autoclaved Difco ${ }^{\mathrm{TM}}$ tryptic soy agar (TSA, Becton, Dickinson, and Co) or Bacto ${ }^{\mathrm{TM}}$ tryptic soy broth (TSB, Becton, Dickinson, and Co.) in order to yield $100 \mathrm{ppm}$ final rifampin concentration, such as $0.1 \mathrm{~mL}$ rif stock to $10 \mathrm{~mL}$ TSB tube, or $10 \mathrm{~mL}$ rif stock to $1,000 \mathrm{~mL}$ TSA medium. 


\section{2. $E$. coli $0157: H 7$ culture preparation}

Two rifampin-resistant (200 ppm) strains of Escherichia coli O157:H7 (MDD20, MDD326) and two rifampin-sensitive strains (MDD19 and MDD 327NA), were kindly provided by Dr. Michelle Danyluk's lab (University of Florida, USA). Rifampin-sensitive strain ATCC 35150 was bought directly from American Type Culture Collection (Manassas, WI). Rifampinsensitive strains were mutated to induce rifampin resistance by transferring a pure culture from TSA plates $\left(37^{\circ} \mathrm{C}, 24\right.$ hours $)$ to $10 \mathrm{~mL}$ TSB-rif 5ppm broth $\left(37^{\circ} \mathrm{C}, 24\right.$ hours $)$, followed by sequential transfer of $0.1 \mathrm{~mL}$ aliquot to TBS containing 10, 20, and 40 ppm rifampin. Turbid cultures (40 ppm rif) were streaked on TSArif200 plates $\left(37^{\circ} \mathrm{C}, 24\right.$ hours $)$, and a single colony was transferred to TSB-rif200 broth to confirm growth. Five rif-resistant E. coli O157$\mathrm{H} 7$ strains were maintained on TSA-rif80 ppm slants at $4^{\circ} \mathrm{C}$ with bi-weekly transfers to fresh TSA-rif80 slants.

For the experimental protocol, five strains were streaked on TSA-rif100 plates $\left(37^{\circ} \mathrm{C}, 24\right.$ hours), followed by three consecutive one loopful transfers to $10 \mathrm{~mL}$ TSB-rif100 tubes ( $37^{\circ} \mathrm{C}, 12$ hours, 12 hours, and 18 hours). A pathogenic cocktail $\left(10 \mathrm{~mL}, 10^{9} \mathrm{cfu} / \mathrm{mL}\right)$ was prepared by mixing $2 \mathrm{~mL}$ of each culture from the third broth. The cocktail was centrifuged (4,300g, 10 minutes, Sorvall RC-5B centrifuge, DuPont Instruments) and washed once in $10 \mathrm{~mL}$ Dulbecco A phosphate buffered saline (PBS, Oxoid, Hampshire, England), followed by final centrifugation $(4,300 \mathrm{~g}, 10$ minutes $)$ and resuspension in $10 \mathrm{~mL} 0.1 \%$ peptone (Bacto peptone, Becton Dickinson and Co, Sparks, USA). Concentration of inoculum was confirmed by serial dilutions in Buffered Peptone Water (BPW, Becton, Dickinson, and Co.) and pour plating using TSA-rif $100\left(37^{\circ} \mathrm{C}\right.$, 24 hours).

\subsection{Tomato preparation, inoculation, and storage for temperature abuse study}

Green mature tomatoes variety Florida 47, unwashed and unwaxed, were acquired for each replication from DiMare Co. (Ruskin, Florida, USA). Each tomato was dry rubbed using clean nitrile gloves before inoculation studies to normalize microflora within tomatoes in the same set.

For each replication, thirty nine mature green tomatoes were inoculated with $0.1 \mathrm{~mL}$ of pathogenic cocktail as 10 spots of equal size around blossom end each $\left(10^{8}\right.$ cfu/tomato). Three sets of four tomatoes plus one tomato for immediate sampling were left uninoculated and served as negative controls. The procedure was carried out in a biosafety hood and tomatoes were allowed to dry for 90 minutes before moving into $25^{\circ} \mathrm{C}, 15^{\circ} \mathrm{C}$, and temperature ramping incubator (see Figure 1 for schedule). A shallow pan with water was placed in each incubator to humidify environment, while temperature and humidity were recorded for four days with 10-minute sampling intervals (Hobo® U12 data logger, Onset Computer Corp, Pocasset, MA). Sets of three inoculated and dried tomatoes with one negative control tomato were tested immediately after drying (day 0, 90 minutes dry), and sampled on day 1, day 2 , day 3 , and day 4 from each incubator.

\section{4. $E$. coli $0157: H 7$ recovery from tomatoes}

To recover pathogen, a single tomato was transferred to $20 \mathrm{~mL} \mathrm{BPW}$ in a stomacher bag and vigorously manually shaken for 30 seconds, rubbed for 30 seconds, and shaken again for 30 seconds. The rinsate was either plated directly or serially diluted in $9 \mathrm{~mL}$ BPW tubes before plating using pour plate method and TSA-rif100 medium. The plates were incubated for 24 hours at $37^{\circ} \mathrm{C}$ before counting.

\subsection{Statistical analysis}

E. coli $\mathrm{O} 157: \mathrm{H} 7$ survival on tomatoes (three replications) was analyzed using multifactorial ANOVA with two factors - storage day (day 1, day 2, day 3, day 4) and storage temperature $\left(15^{\circ} \mathrm{C}, 25^{\circ} \mathrm{C}\right.$, and ramp) influencing bacterial counts. If influence of factors or their combination was significant $(p<0.05)$, means were separated using Fisher LSD procedure. 
Average temperature for each datapoint for all replications for ramping temperature over 4-day sampling period with 10-minute intervals with overall standard deviation for each datapoint were calculated. Relative humidity values were averaged for all datapoints for each replication for $25^{\circ} \mathrm{C}, 15^{\circ} \mathrm{C}$, and ramping temperature over 4 day sampling period with 10-minute intervals with overall standard deviation for each replication calculated.

\section{Results and discussions}

\subsection{Physical monitoring of storage conditions}

Results for continuous ramp temperature monitoring over time in temperature-abused inoculated tomatoes and negative controls are shown in Figure 1. Relative humidity in storage incubators are shown under Figure 2 footnote.

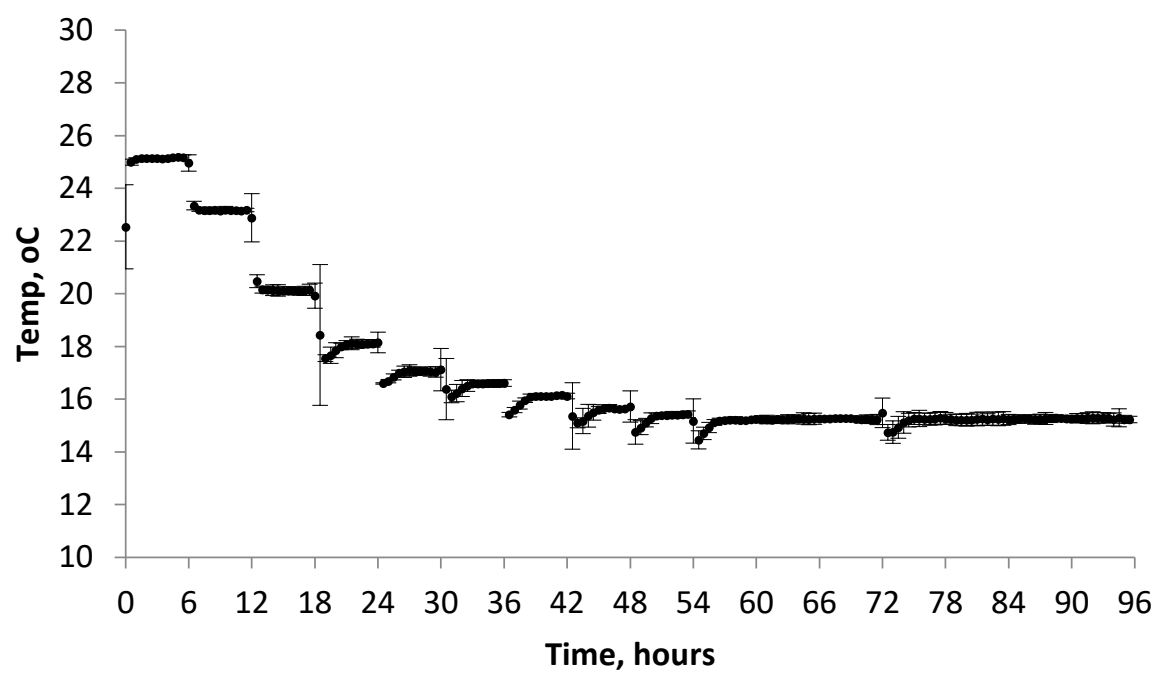

Figure 1. Temperature changes in simulating tomato temperature abuse incubator $\left(25^{\circ} \mathrm{C}\right.$ to $15^{\circ} \mathrm{C}$ decrease within four days). Average values of each datapoint for three replications (combined) with standard deviation included.

\subsection{E. coli 0157:H7 enumeration}

As expected, E. coli $\mathrm{O} 157: \mathrm{H} 7$ numbers declined $1.5 \log$ units from theoretical inoculation level of $6.8 \pm 0.1 \mathrm{SD} \log _{10} \mathrm{cfu} / \mathrm{mL}$ of rinsate to $5.3 \pm 0.1 \mathrm{SD} \log _{10} \mathrm{cfu} / \mathrm{mL}$ upon 90 minutes drying, and continued to decline rapidly during storage at both $25^{\circ} \mathrm{C}$ and $15^{\circ} \mathrm{C}$, as well as temperature abuse conditions, resulting in final counts of $1.5,2.4$, and $2.6 \log _{10} \mathrm{cfu} / \mathrm{mL}$ on day 4 for $25^{\circ} \mathrm{C}, 15^{\circ} \mathrm{C}$, and ramp, respectively (Figure 2).

There was a significant influence of both factors, storage day and storage conditions, as well as their interaction, on E.coli O157:H7 counts $(\mathrm{p}<0.05$, Figure 2$)$. It appeared that the biggest decline was observed at $25^{\circ} \mathrm{C}$ on day 4 , suggesting that cool conditions might have preservation effect on the bacterium. Interestingly, final pathogen counts under ramp conditions $\left(25^{\circ} \mathrm{C}\right.$ to $\left.15^{\circ} \mathrm{C}\right)$ were not significantly different from the cool storage $\left(15^{\circ} \mathrm{C}\right)$ on day 4 ( $p>0.05)$, suggesting that both fast cooling and slow cooling support survival, while higher temperature storage $\left(25^{\circ} \mathrm{C}\right)$ accelerate bacterial die-off. Similarly, Lang et al. (2004) showed that $E$. coli $\mathrm{O} 157: \mathrm{H} 7$ counts in 5\% horse serum on the dried spot-inoculated tomatoes decreased $1.07 \operatorname{logs}$ after 1 hour drying and $3.17 \operatorname{logs} 24$ hours post-drying from initial $7.22 \log _{10}$ cfu/tomato. Møretrø et al. (2010) showed that twelve Shiga-toxin producing E. coli strains, each analyzed separately, declined upon dessication in Brain Heart Infusion broth (BHI) on the stainless steel (type 304) from 6-7 logs to 
3-5 logs on day 1 and 2-3.5 $\log$ s on day 7. Follow-up studies comparing BHI and water, $12^{\circ} \mathrm{C}$ and $20^{\circ} \mathrm{C}, 70 \% \mathrm{RH}$ and $80 \% \mathrm{RH}$, showed beneficial effect of $\mathrm{BHI}, 12^{\circ} \mathrm{C}$, and $70 \%$ air relative humidity for $E$. coli survival. It can be argued that microorganisms in the dried up inoculum survive better at lower humidity (no metabolic activity) compared to high humidity, as well as at lower temperature, because at otherwise conditions exhausted stationary culture, still metabolically active, slowly dies off.

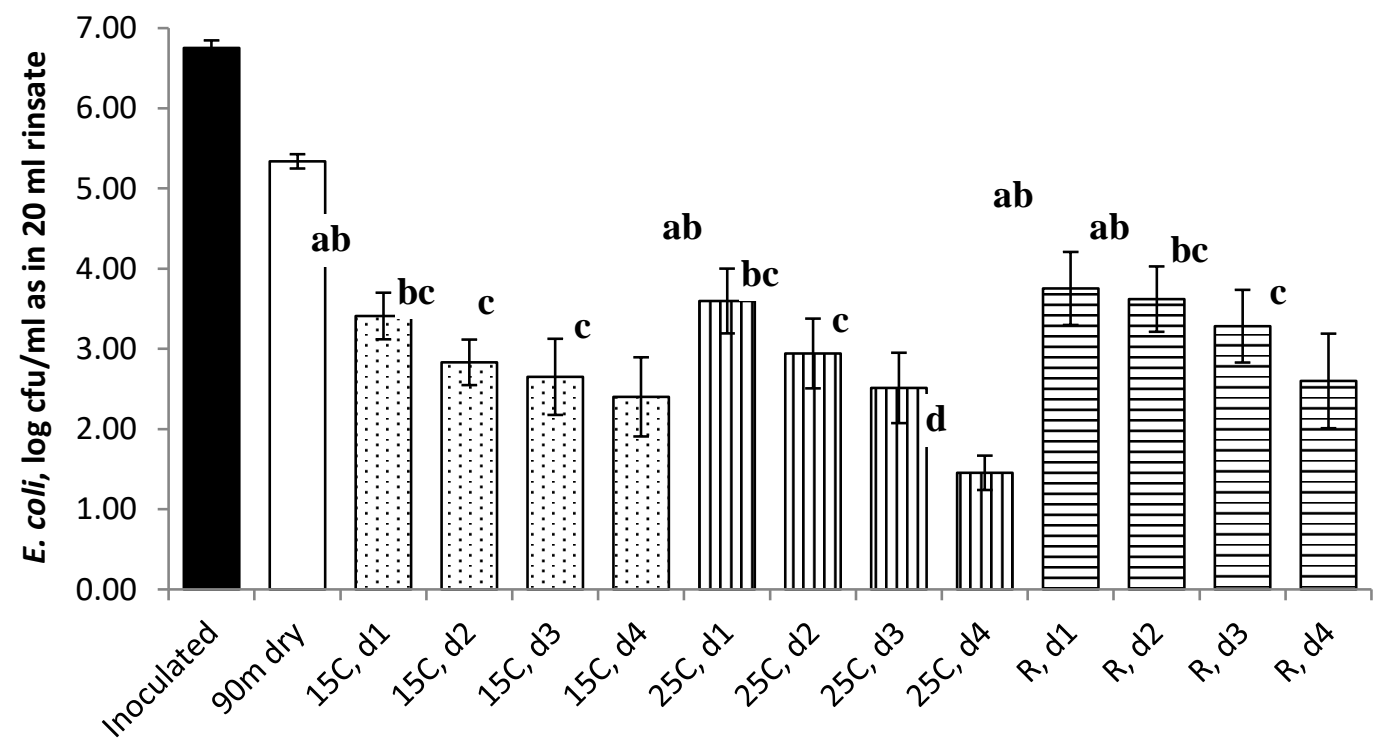

Figure 2. Recovery of $E$. coli $\mathrm{O} 157: \mathrm{H} 7$ from inoculated tomatoes either immediately after drying (90 min dry), or after storage for four days (d1-d4) at different temperatures $\left(* 15^{\circ} \mathrm{C}, * * 25^{\circ} \mathrm{C}, * * *\right.$ ramp).

Counts expressed as $\log _{10} \mathrm{cfu}$ per $\mathrm{mL}$ recovered from $20 \mathrm{~mL}$ rinsate. Inoculated level calculated theoretically based on stationary culture concentration and is shown for reference. Means with the same letters are not significantly different $(\mathrm{p}>0.05)$.

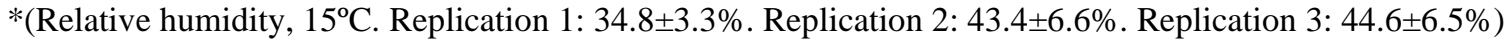

$* *$ (Relative humidity, $25^{\circ} \mathrm{C}$. Replication 1: $58.8 \pm 3.6 \%$. Replication 2: $59.4 \pm 3.8 \%$. Replication 3: $59.5 \pm 4.1 \%$ )

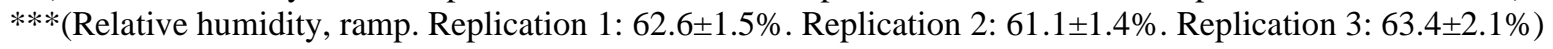

\section{Conclusions}

To summarize, E. coli O157:H7 did not survive well on the intact surface of tomatoes at $25^{\circ} \mathrm{C}$, but lower temperature at $15^{\circ} \mathrm{C}$ might stimulate pathogen survival.

\section{References}

Batu, A. (2003). Temperature effects on fruit quality of mature green tomatoes during controlled atmosphere storage. International Journal of Food Sciences and Nutrition, 54(3), 201-8.
Beuchat, R.Y., Ryu, J.H. (1997). Produce handling and processing practices. Emerging Infectious Diseases, 3, 439-65.

CDC. Centers for Disease Control and Prevention. (2002). Outbreak of Salmonella serotype Javiana infections-Orlando, Florida, June 2002. Morbidity and Mortality Weekly Report, 51, 683-4.

Croby, R., Lanni, V., Kistler, V., Dato, V., Weltman, A., Yozviak, C., Waller, K., Nalluswami, K., Moll, M., Lockett, J., Montgomery, S., Lyuch, M., Braden, C., Gupta, S.K., Dubois, A. (2005). Outbreaks of Salmonella infections associated with 
eating Roma tomatoes-United States and Canada, 2004. Morbidity and Mortality Weekly Report, 54, 325-8.

Cummings, K., Barrett, E., Mohle-Boetani, J.C., Brooks J.T., Farrar, J, Hunt, T., Fiore, A., Komatsu, K., Werner, S.B., Slutsker, L. (2001). A multistate outbreak of Salmonella enterica serotype Baildon associated with domestic raw tomatoes. Emerging Infectious Diseases, 7, 1046-8.

Das, E., Gurakan G.C., Bayindirli A. (2006). Effect of controlled atmosphere storage, modified atmosphere packaging and gaseous ozone treatment on the survival of Salmonella Enteritidis on cherry tomatoes. Food Microbiology, 23, 430-38.

Hirai, Y. (1991). Survival of bacteria under dry conditions; from a viewpoint of nosocomial infection. Journal of Hospital Infection, 19(3), 191-200.

Inaba, M., Chachin K. (1989). Hightemperature stress and mitochondrial activity of harvested mature-green tomatoes. Journal of the American Society for Horticultural Science, 114(5), 809-14.

Iturriaga, M.H., Tamplin, M.L., Escartín, E.F. (2007). Colonization of tomatoes by Salmonella Montevideo is affected by relative humidity and storage temperature. Journal of Food Protection, 70(1), 30-4.

Kader, A.A., Morris, L.L., Stevens, M.A., Albright-Holton, M. (1978). Composition and flavor quality of fresh market tomatoes as influenced by some postharvest handling procedures. Journal of the American Society of Horticultural Sciences, 103(1), 613.

Lang, M.M., Harris, L.J., Beuchat, L.R. (2004). Evaluation of inoculation method and inoculum drying time for their effects on survival and efficiency of recovery of Escherichia coli O157:H7, Salmonella, and Listeria monocytogenes inoculated on the surface of tomatoes. Journal of Food Protection, 67(4), 732-41.

Møretrø, T., Heir, E., Mo, K.R., Habimana, O., Abdelgani, A., Langsrud, S. (2010). Factors affecting survival of Shigatoxin-producing Escherichia coli on abiotic surfaces. International Journal of Food Microbiology, 138, 71-7.

Mulholland, B. J., Edmondson, R. N., Fussell, M., Basham, J., Ho, L. C. (2003). Effects of high temperature on tomato summer fruit quality. The Journal of Horticultural Science and Biotechnology, 78(3), 365-74.

Shi, X., Namvar, A., Kostrzynska, M., Hora, R., Warriner, K. (2007). Persistence and growth of different Salmonella serovars on pre- and postharvest tomatoes. Journal of Food Protection, 70(12), 2725-31.

Schilling, M.W., Yoon, Y., Tokarskyy, O., Pham, A.J., Williams, R.C., Marshall, D.L. (2009). Effects of ionizing irradiation source and hydrostatic pressure on Escherichia coli O157:H7 inactivation, chemical composition, and sensory acceptability of ground beef patties. Meat Science, 81, 705-10.

Tokarskyy, O., Marshall, D.L., Schilling, M.W., Willeford, K.O. (2009). Comparison of methods to verify end point cooking temperature of Channel catfish (Ictalurus punctatus) fillets. Journal of Muscle Foods, 20, 325-40.

Tokarskyy O., De J., Fatica M. K., Brecht J., Schneider K.R. (2018). Survival of Escherichia coli O157:H7 and Salmonella on bruised and unbruised tomatoes from three ripeness stages at two temperatures. Journal of Food Protection, 81(12), 202833.

Tokarskyy, O., Schneider, K.R. (2019). Influence of temperature, humidity, and diluent type on survival of Salmonella spp. on the surface of raw tomatoes. Potravinarstvo, 13(1), 325-30.

Tokarskyy, O., Korda, M. (2019a). Microbiological comparison of visibly dirty and visibly clean mature green tomatoes before and after treatments with deionized water or chlorine in model overhead spray brush roller system. Potravinarstvo, 13(1), 779-83. 
Tokarskyy, O., Korda, M. (2019b). Influence of suspension liquid total solids on $E$. coli O157:H7 survival and transfer efficacy between green tomatoes and cardboard. Potravinarstvo, 13(1), 941-9.

USDA-ERS. United States Department of Agriculture, Economic Research Service. Loss-adjusted food availability data. (2016). Available at https://www.ers.usda.gov/dataproducts/chart-gallery/gallery/chartdetail/?chartId $=58340 \quad$ Last accessed 01/05/2020.

Zhuang, R.Y., Beuchat, L.R., Angulo, F.J. (1995). Fate of Salmonella Montevideo on and in raw tomatoes as affected by temperature and treatment with chlorine. Applied and Environmental Microbiology, 61(6), 2127-31.

\section{Acknowledgment}

The author is grateful to Dr. Keith R. Schneider and his lab at the Department of Food Science and Human Nutrition, University of Florida, USA, for resources in his lab to conduct these experiments. 